\title{
Reconfiguration Cost Analysis Based on PetriNet for Manufacturing System
}

\author{
Jie CHEN ${ }^{1}$, Liangwei ZHANG ${ }^{1}$, Jianqiang LUO $^{2}$ \\ ${ }^{1}$ School of Economic \& Management, Nanjing University of Science \& Technology, China; ${ }^{2}$ School of Business Administration, \\ Jiang Su University, Zhenjiang, China. \\ Email: Jie_chen163@163.com
}

Received August $7^{\text {th }}, 2009$; revised August 27 $7^{\text {th }}, 2009$; accepted September $16^{\text {th }}, 2009$.

\begin{abstract}
Nowadays, manufacturers are faced with severe challenges to response rapidly to changing demands and meet various customers' needs with respect to production volume and product profile. Reconfigurable manufacturing paradigm was proposed as an advanced manufacturing philosophy to enhance the adaptability and flexibility of manufacturing systems. By physical and logical reconfiguration, Reconfigurable Manufacturing System (RMS) is able to fulfil customers' needs in a cost-effective way by making full use of the resources currently available. This paper focuses on studying of reconfiguration cost of such systems. In this paper, DEDS modelling method Petri Net is used to construct the model for reconfiguration process of RMS which includes physical reconfiguration cost factors and conjunction matrix is used to describe the production processes. By highlighting the differences in the process set before and after reconfiguration, the reconfiguration principles have been proposed to describe and guide the process of the manufacturing system reconfiguration. The simulation example is given to prove the validation of the proposed model.
\end{abstract}

Keywords: Reconfigurable Manufacturing System, Petri Net, Reconfiguration Cost, Process Set, Conjunction Matrix

\section{Introduction}

In a globally competitive market for products, manufacturers are faced with an increasing need to improve their flexibility, reliability, and responsiveness to meet the demands of their customers. Reconfigurable Manufacturing Systems (RMS) have become an important manufacturing paradigm, because they can reconfigure their capacities to response the changing environment and requirements by providing changed capacities and functions at low cost and rapid time [1].

The concept of RMS which was introduced by Y. koren et al. at the Engineering Research Centre of the University of Michigan (UM) in the mid 1990s, was listed the first one of the top $10 \mathrm{key}$ technologies for future manufacturing industry by NRC (United States National Research Council) [2]. RMS may have two levels of reconfiguration: physical reconfiguration and logical reconfiguration, including production organization, products, processes, manufacturing system or production line, machines and the relevant information system reconfiguration [3]. The outstanding advantage is its reconfiguration at low cost and rapid time [4]. Therefore, the related research work is rich in literature. Our study is focused on the reconfiguration cost analysis for manu-

\section{facturing system.}

There are several studies related to reconfiguration cost modelling of RMS. Some representative cases are cited as follows:

On the base of the evaluation index system, some synthetical evaluation methods, such as Analytical Hierarchy Process (AHP) and grey fuzzy, are proposed to evaluate the total performance of RMS [5-8]. Some researchers introduce the Petri Net to describe the reconfiguration process of RMS, and afterwards, applied it into the performance assessment of the RMS [10-13]. Considering physical reconfiguration cost and the relevant logical reconfiguration penalty cost, the cost function of the model is built up, and a Dynamic Programming (DP) approach is manipulated for the development of optimal capacity plans [14]. Considering the effects of economical factor, salvage factor and time-value factor during the life-cycle, Liang gives an approximate reconfiguration cost model and the trend analysis of the influential factors [15]. The researches mentioned above provide primary modelling and analysis framework. But, most of them only focus on the economical evaluation factors or indexes of RMS, however, the cost factors calculation are either given qualitatively or estimated quantitatively with little relation to the system reconfiguration solutions. 
This paper only focuses on how to calculate the physical reconfiguration cost which is produced by rearranging the facilities with the changed shop floor task. We assume that the physical reconfiguration cost only include the cost factors which are produced by adding, eliminating and re-arranging facilities without considering relevant management changing cost. In this paper, Petri Net is used to construct the model for reconfiguration process of RMS which includes physical reconfiguration cost factors and conjunction matrix is used to describe the production processes. By dividing and differentiating the process set before and after reconfiguration, the reconfiguration principles have been described in the model which can be used to guide the process of the manufacturing system reconfiguration as well. The physical reconfiguration cost of RMS can be calculated through summing up the cost of adding new equipments, removing the original ones and re-arranging them by referring to graph theory and linear algebra knowledge related. Finally, a simulation case study is presented to validate the feasibility and rationality of the model, in which Matlab simulation is used to obtain reconfiguration cost.

\section{Modelling to RMS Reconfiguration Process Via Petri Net}

\subsection{Description of the Problem}

Cost-effective is one of the most important characters of RMS, whereby, the reconfiguration cost has become a significant factor to evaluate the performance of RMS. However, there is not a unified definition of the reconfiguration cost up to now. Some researchers only consider the cost of one time for system reconfiguration. So the configuration cost is composed of physical reconfiguration cost and logical reconfiguration cost [14]. The others, such as Liang, pointed that reconfiguration cost includes initial investment, adjustment cost and salvage during the whole life-cycle [15]. As we know, the logical reconfiguration cost can not be defined quantitatively. So, in this paper, we only consider manufacturing system physical reconfiguration cost, which refers to the cost which results from rearranging the facilities in shop floors. We assume that the physical reconfiguration cost only include the cost factors which are produced by adding, eliminating and re-arranging facilities in shop floors.

RMS is a typical Distributed Events Dynamic System (DEDS). As DEDS process modelling tool, Petri Net can describe parallel, sequential, synchronized and conflictive process structures precisely, which is popularly used to model manufacturing systems. In this section, we take advantages of Petri Net to build up the reconfiguration cost model in order to provide support for system reconfiguration solution evaluation.
Combination with the Petri Net model in which cost is introduced, the reconfiguration cost will be calculated by comparing changes occur on modelling elements in the reconfiguration process. The paper has an instruction function to optimize RMS reconfiguration solution, besides it can provide reconfiguration cost data to support appraisement of RMS as well.

\subsection{Definition of the Petri Net Model}

Firstly, we define a Petri Net, which consists of 6 elements. It can be expressed as $P N=(P, T, O, I, C A, C R)$, where:

1) $P=\left\{p_{1}, \ldots, p_{n}\right\}$ is a finite place set, corresponding to the equipment set of manufacturing system. $T=\left\{t_{1}, \ldots, t_{n}\right\}$ is a finite transition set, corresponding to the process set of manufacturing system. Conditions $P \cap T=\varnothing$ and $P \bigcup T \neq \varnothing$ should be satisfied.

2) $O$ is the output function, corresponding to output place set of every transition. $I$ is the input function, element of which is a set either, corresponding to input place set of every transition.

3) $C A$ represents average cost to install new equipment, while $C R$ indicates disassemble it.

\subsection{Assumed Conditions}

The model using Petri Net to describe reconfiguration process of RMS is based on hypothesis as follows:

1) Each stage of the production process corresponds to only one equipment or machine. It shows that the stage of the process is executed by the designated equipment.

2) There is only one immediate successor activity for each stage of the production process.

3) A virtual output port of the production process act as the immediate successor activity of the last working procedure should be added to the model.

4) The production process carries out strictly in accordance with the work procedure order.

5) Only equipment installation, disassembly and rearrange to the original equipment will be involved in the reconfiguration process. The equipment rearrangement can be viewed as remove original equipment then install it according to new logic relationship.

\subsection{The Principle to Generate Basic Petri Net from Production Process}

According to the characterization of RMS and Petri Net modelling method, we formulate the principles which can be used to generate a basic Petri Net from production process of manufacturing system. They can be concluded as follows:

1) Use conjunction matrix to denote production process.

Assume that the production process of manufacturing system is denoted by directed graph $G(M, R)$, among 
which $M$ is the vertex set and $R$ is the edge set. $M=$ $\left\{m_{1}, \ldots, m_{n}\right\}$ represents the production stage in the process where $n$ is a sum of procedure. $R$ represents the conjunction relationship of all the working procedure in $M$. Then n-order phalanx $A(G)=\left(a_{i, j}\right)$ is called the conjunction matrix of $G$. Matrix can be used to describe above directed graph, a matrix must correspond to a directed graph where node number has been marked up. Where

$$
a_{i, j}=\left\{\begin{array}{lc}
1 & m_{i} \text { point } \text { to } m_{j} \\
0 & \text { others }
\end{array} .\right.
$$

2) Establish a mapping relationship $f$ from vertex set $M$ of $G$ to transition set $T$ of $P N$, as $T=f(M)=\left\{t_{1}, t_{2}, \ldots, t_{n}\right\}$.

3) Establish a mapping relationship $O$ from transition set $T$ of $P N$ to place set $P$, as for $\forall t \in T$, we have $p_{i}=O\left(t_{i}\right)$ and $P=O(T)=\left\{p_{1}, \cdots, p_{n}\right\}$.

4) Sort the output function $O(t), t \in T$ in accordance with the process order in set $M$ to form a row vector $O=\left(O\left(t_{1}\right), O\left(t_{2}\right), \ldots, O\left(t_{n}\right)\right)$. Each element of the set $O$, $O\left(t_{i}\right)$ is a set either, means the output place set of transition $t_{i}$, which refers to equipment.

5) According to the formula $I=O \times A$, an n-dimensional row vector $I=\left(I\left(t_{1}\right), I\left(t_{2}\right), \ldots, I\left(t_{n}\right)\right)$ can be derived. Each element of the set $I, I\left(t_{i}\right)$ is a set either, means the input place set of transition $t_{i}$. As for $\forall I\left(t_{i}\right)=\varnothing$, we can define $I\left(t_{i}\right)=p, \quad p \notin P \mathrm{v}$, then deposit it into place set as an input port of the system.

6) List the cost of adding new equipment and remove an original one of all the equipment in accordance with the process order in set $\mathrm{M}$ as $C A\left(C A_{1}, C A_{2}, \ldots, C A_{n}\right)$ and $C R\left(C R_{1}, C R_{2}, \ldots, C R_{n}\right)$. These two vectors represent the cost of installing and disassembling equipment respectively corresponding to the production process.

\subsection{Reconfiguration Rules of the Basic Petri Net Model}

RMS is able to manufacture the part families at the same time, which is configured to produce each family at different volume to satisfy customer demands.

The manufacturing system $S_{a}$ produces part family "a" before reconfiguration, while $S_{b}$ produce part family " $b$ " after reconfiguration. The work flow chart of $S_{a}$ can be expressed as $G_{a}\left(M_{a}, R_{a}\right)$, the conjunction matrix is $A_{a}$ and the Petri Net model is $P N_{a}\left(P_{a}, T_{a}, O_{a}, I_{a}, C A_{a}, C R_{a}\right)$. Correspondingly, the work flow chart of $S_{b}$ is $G_{b}\left(M_{b}, R_{b}\right)$, the conjunction matrix is $A_{b}$ and the Petri Net model of $S_{b}$ is $P N_{b}\left(P_{b}, T_{b}, O_{b}, I_{b}, C A_{b}, C R_{b}\right)$. Suppose that the mapping relationship from production process set $M$ to tran- sition set $T$ is $f$, which can be expressed as $T=f(M)$, another mapping relationship $O$ is from transition set to output place set $O(T)$.

Based on the symbol definitions above, we may formulate the reconfiguration rules from system $S_{a}$ to $S_{b}$ as follows:

1) Divide the process set before and after reconfiguration.

Assumed that the set $M^{0}=M_{a} \cap M_{b}$ (the set size is $u$ ) represents process set which haven't been adjusted. The set $M^{+}=M_{b}-M^{0}$ (the set size is $v$ ) represents process set added in the reconfiguration process. The set $M^{-}=M_{a}-M^{0}$ (the set size is $w$ ) represents process set removed in the reconfiguration process. Then $T_{a}^{0}=f\left(M^{0}\right)$ represents transition set in correspond with process set which haven't been adjusted and $P_{a}^{0}=O\left(T_{a}^{0}\right)$ represents the output place in correspond to $T_{a}^{0}$.

2) $P N_{b}$ inherits the transition set and input, output place set of $P N_{a}$, then delete the input place of the system.

Suppose $T_{b}^{0}$ is the transition set of $M^{0}$ accordingly, as for $\forall m \in M^{0}$ we may have $T_{b}^{0}=f\left(M^{0}\right)=T_{a}^{0}$, assume that $P_{b}^{0}$ is the output place of $T_{b}^{0}$ accordingly, then we have $P_{b}^{0}=O\left(T_{b}^{0}\right)=P_{a}^{0}$.

With regard to $\forall t \in T_{b}^{0}$, we have $O_{b}(t)=O_{a}(t)$.

At the same time, regarding $\forall t \in T_{b}^{0}$, because of the one-to-one mapping relationship between process $\mathrm{m}$ and transition $t$, we can determine a unique process $m=f^{-1}(t)$ by $t$.

Define a column vector $V$ of which the row is the set of $M^{0}$ and the column is $m$ determined by $t$ in the conjunction matrix $A(G)$, expressed as follows.

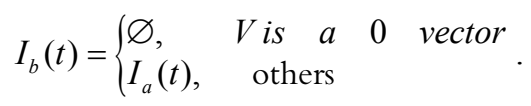

3) Add the transition set and input place of $M^{+}$into $P N_{a}$

Suppose $T_{b}^{+}$is the transition set of $M^{+}$, that is $T_{b}^{+}=f\left(M^{+}\right)$, based on the definition of $M^{+}$and the one-to-one mapping relationship $f$ between process and transition set, we have $T_{b}^{+} \cap T_{a}=\varnothing$, so we can come to the conclusion that $T_{b}=T_{b}^{0} \cup T_{b}^{+}$.

Suppose $P_{b}^{+}$is the output place of $T^{+}$, that is $P_{b}^{+}=O\left(T_{b}^{+}\right)$, on the basis of the definition of $T_{b}^{+}$and the one-to-one mapping relationship $O$ between transition set and output place set, we have $P_{b}^{+} \cap P_{a}=\varnothing$, so we can come to the conclusion that $P_{b}=O\left(T_{b}^{0}\right) \cup O\left(T_{b}^{+}\right)$. 
4) Adjust the input place in accordance with the transition set of $P N_{b}$. Then regenerate a new input port of the system.

Select specific row and column from $A_{a}$ to construct a vector $C_{a}$ and $C_{b}$ as

$$
\begin{aligned}
& M^{0} \\
& C_{a}=M^{0}\left[\begin{array}{l}
A_{a}\left(M^{0} \times M^{0}\right) \\
A_{a}\left(M^{-} \times M^{0}\right)
\end{array}\right] \\
& M^{0} \\
& C_{b}=\begin{array}{l}
M^{0} \\
M^{+}
\end{array}\left[\begin{array}{l}
A_{b}\left(M^{0} \times M^{0}\right) \\
A_{b}\left(M^{+} \times M^{0}\right)
\end{array}\right. \\
& M^{+} \\
& \left.\begin{array}{l}
A_{b}\left(M^{0} \times M^{+}\right) \\
A_{b}\left(M^{+} \times M^{+}\right)
\end{array}\right]
\end{aligned}
$$

Define

$$
\begin{aligned}
& A_{a}^{\prime}=E_{a 1} \times C_{a} \times E_{a 2} \\
& A_{b}^{\prime}=E_{b} \times C_{b}
\end{aligned}
$$

Assumed that the row of $\left(A_{b}^{\prime}-A_{a}^{\prime}\right)$ correspond to process $m_{i}$ while the column of it correspond to process $m_{j}$. We can see from the rules of matrix operation that there are only 3 elements $\{-1,0,1\}$ in matrix $\left(A_{b}^{\prime}-A_{a}^{\prime}\right)$, in which 1 stands for cancelling the conjunction from $m_{i}$ to $m_{j}$, that is disassemble the equipment corresponding with process $m_{i}, 0$ means there are no change between $m_{i}$ and $m_{j}, 1$ represents add a new connection from $m_{i}$ to $m_{j}$, that is install new equipment corresponding with process $m_{i}$.

Where

$$
E_{a 1}=\left[\begin{array}{cc}
E_{u} & 0_{u \times w} \\
0_{v \times u} & 0_{v \times w} \\
0_{w \times u} & E_{w}
\end{array}\right], E_{a 2}=\left[\begin{array}{ll}
E_{u} & 0_{u \times v}
\end{array}\right], \quad E_{b}=\left[\begin{array}{l}
E_{u+v} \\
0_{w \times(u+v)}
\end{array}\right] .
$$

$E_{u}$ is a $u$-dimensional unit matrix, $E_{v}$ is a $v$-dimensional unit matrix, $E_{w}$ is a $w$-dimensional unit matrix, 0 is a zero matrix, the subscript of which is the dimension of it.

Assumed that the row vector $O$ and $I_{l}$ are,

$$
\begin{aligned}
& O=\left[O\left(T_{a}^{0}\right), O\left(T_{b}^{+}\right), O\left(T_{a}^{-}\right)\right] \\
& I_{1}=[I_{b}^{\prime}(t), \overbrace{\varnothing, \ldots, \varnothing}^{w}]
\end{aligned}
$$

Where $I_{b}^{\prime}(t)$ is a $u$-dimensional row vector obtained by sorting $I_{b}(t)$ according to the process order in $M^{0}$ for $t \in T_{b}^{0}$. Each element in the set $I_{b}^{\prime}(t)$ is a set and there are $w$ empty sets in it.

From the Formula (1), (2), (3) and (4)

We may know that $I_{2}=I_{1}+O \times\left(A_{b}^{\prime}-A_{a}^{\prime}\right)$. Assign the value of $I_{2}$ to $I_{b}(t)$ which is the place set corresponding with transition set in $T_{b}$ by turns. As for $\forall t \in T_{b}$, if
$I_{b}(t)=\varnothing$, we define $I_{b}(t)=\{p\} \quad\left(p \notin P_{a}\right.$, the input port of the system), then keep it in the place set.

\section{Calculation of the Reconfiguration Cost}

The RMS reconfiguration process can be realized by equipment rearrangement and reuse or update system and subsystem configuration in the original scope of design. According to the definition of Petri Net and hypothesis to the model, each equipment has its installation cost $C A$ and disassemble cost $C R$ (cost of the system output port is 0$)$. From the definition of the elements of above matrix $\left(A_{b}^{\prime}-A_{a}^{\prime}\right)$, we may see which processes would be rearranged, added and deleted, similarly, we can see which equipment would be installed and disassembled.

Suppose $C_{A T}$ is the total cost of equipment installation in the reconfiguration process, initialize $C_{A T}=0$. Make $C A_{i}$ be the installation cost of $i^{\text {th }}$ equipment. Search the processes in accordance with $i^{\text {th }}$ equipment in the matrix $\left(A_{b}^{\prime}-A_{a}^{\prime}\right)$, if met with 1 , let $C_{A T}=C_{A T}+\mathrm{CA}_{\mathrm{i}}$, we may get the total cost of equipment installation by traversing all the elements of $\left(A_{b}^{\prime}-A_{a}^{\prime}\right)$.

Similarly, suppose $C_{R T}$ is the total cost of equipment disassemble in the reconfiguration process, initialize $C_{R T}=0$. Make $C R_{i}$ be the disassemble cost of $i^{\text {th }}$ equipment. Search the processes in accordance with $i^{\text {th }}$ equipment in the matrix $\left(A_{b}^{\prime}-A_{a}^{\prime}\right)$, if met with -1 , let $C_{\mathrm{R} \text { 总 }}=C_{\mathrm{R}} \mathrm{R}_{\mathrm{c}}+C R_{i}$, we may get the total cost of equipment disassemble by traversing all the elements of $\left(A_{b}^{\prime}-A_{a}^{\prime}\right)$

Thus, the total cost in the reconfiguration process based on the hypothesis above is: $C_{T}=C_{A T}+C_{R T}$

We can calculate $C_{T}$ by following steps:

1) Define a $(u+v+w)$-by- $(u+v)$ matrix $I$, elements of which are the square of elements in the matrix $\left(A_{b}^{\prime}-A_{a}^{\prime}\right)$

2) Suppose $p_{i}=\frac{C A_{i}-C R_{i}}{2}$, and $q_{i}=\frac{C A_{i}+C R_{i}}{2}$, sort $p_{i}$ and $q_{i}$ by the below order to form vector $G$ and $H$ respectively.

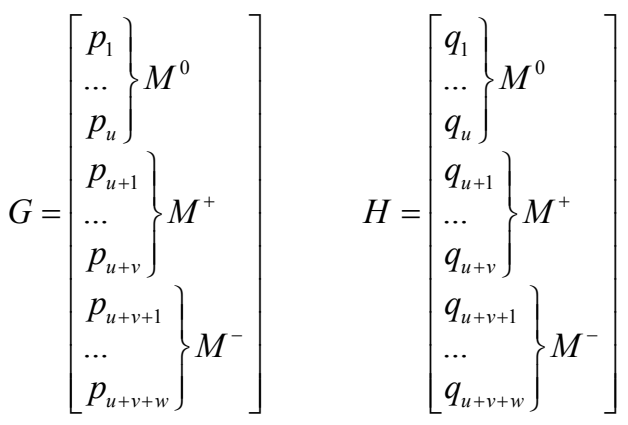

3) $\operatorname{Suppose} \operatorname{ones}(x, y)$ is a 2-dimensional matrix, row 
and column number of which is $x$ and $y$ respectively. The elements of ones $(x, y)$ are 1 . Define the matrix operator ".*" as multiply the elements in the same position of 2 matrix with the same rank.

4) Finally, we can obtain the total cost as:

$$
C_{T}=C_{A \text { 总 }}+C_{R \text { 总 }}=\sum_{i=1}^{u+v+w} \sum_{j=1}^{u+w} J_{i, j}
$$

Where,

$$
\begin{gathered}
J=(G+H) / 2 * \text { ones }(1, u+v) *^{*}\left(\text { ones }(u+v+w, u+v){ }^{*} I\right) \\
+(G-H) / 2 * \text { ones }(1, u+v) .{ }^{*}\left(A_{b}^{\prime}-A_{a}^{\prime}\right) \\
J_{i, j} \text { is the } i^{\text {th }} \text { row and } j^{\text {th }} \text { column element of matrix } J .
\end{gathered}
$$

\section{An Example Application}

A high-tech company which produces aluminium clad/ unclad strip and sheet for heat exchanger in automotive industry is investigated here. The corporation, a typical make-to-order enterprise, would adjust its process set and process order according to different customer requirements. The main equipment of the company could be summarized below: melting furnace, caster machine, homogenizing furnace, saw machine, scalper machine, polish machine, cladding line, preheating furnace, hot-mill, and cold-mill, annealing furnace, stretch level machine, high-gauge slitter and cut-to-length machine. Aided-equipment provides cycle water, electricity and gas for the entire process, which we won't take into account in this case.

Suppose the current production specification is S-type heat-sink, the work flow chart is shown as Figure 1.

There are 13 procedures and 9 stages in that production process, and the process is reflected by the equipment name in the work flow chart. It should be noted that a virtual work procedure "system output" was involved in the production process as the last stage according to the hypothesis. The stage 9 has no corresponding equipment and the installation and disassemble cost are 0 as well.

When the requirements of order change to T-type heat-sink, the production process must be geared on the basis of the original process, such as add/remove some processes and alter the process order that wouldn't been adjusted. It is just like the reconfiguration process of RMS. There are 2 alternate solutions that can fully satisfy the needs to the T-type heat-sink of the new order. Yet the cost of the 2 solutions are so different from each other, we should consider how to get cost data using the model above precisely and then compare the 2 solutions to select a economical one.

Solution 1 adds some new processes to the original process like annealing furnace, cold mill2 and cut-tolength machine. Polish machine, cladding line and highgauge slitter are removed. There is some adjustment to the position of the homogenizing furnace either. The work flow chart of solution 1 can be described in Figure 2.

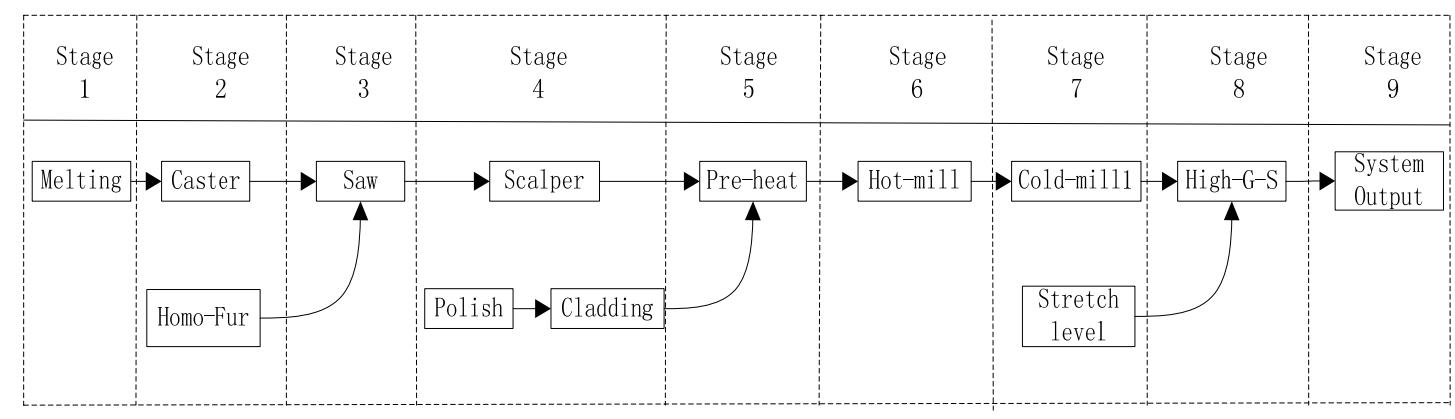

Figure 1. Work flow chart of the original system configuration

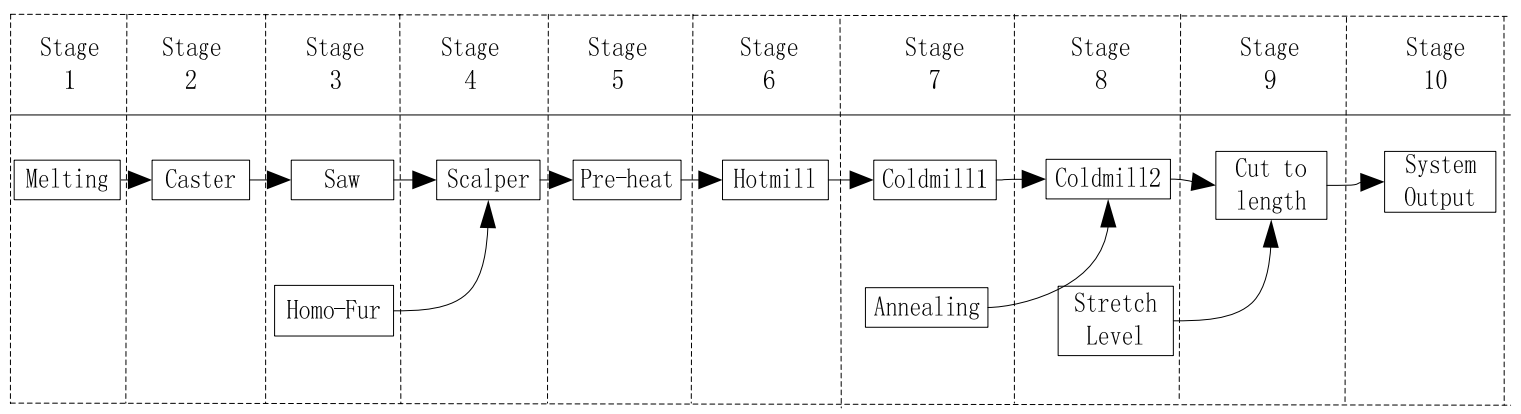

Figure 2. Work flow chart of the Solution 1 


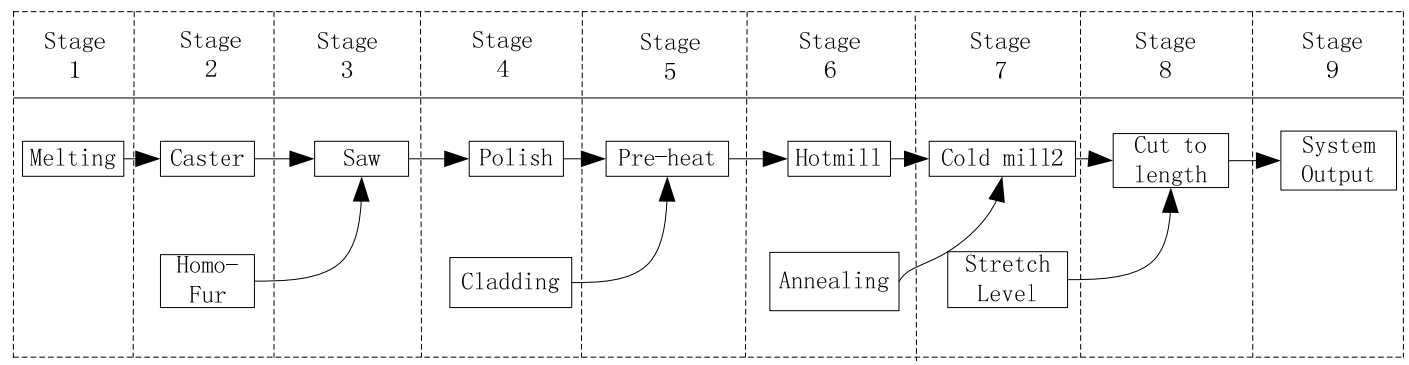

Figure 3. Work flow chart of the Solution 2

Table 1. Codes of each process

\begin{tabular}{llclcl}
\hline$m_{1}$ & Melting furnace & $m_{2}$ & Caster machine & $m_{3}$ & Homogenizing furnace \\
\hline$m_{4}$ & Saw machine & $m_{5}$ & Scalper machine & $m_{6}$ & Polish machine \\
$m_{7}$ & Cladding line & $m_{8}$ & Pre-heating furnace & $m_{9}$ & Hot-mill \\
$m_{10}$ & Cold-mill1 & $m_{11}$ & Stretch Level & $m_{12}$ & High-gauge slitter \\
$m_{13}$ & System Output & $m_{14}$ & Annealing furnace & $m_{15}$ & Cold-mill 2 \\
$m_{16}$ & Cut-to-length & & & & \\
\hline
\end{tabular}

$\begin{array}{ccccccccccccc} & \mathrm{m} 1 & \mathrm{~m} 2 & \mathrm{~m} 3 & \mathrm{~m} 4 & \mathrm{~m} 5 & \mathrm{~m} 6 & \mathrm{~m} 7 & \mathrm{~m} 8 & \mathrm{~m} 9 & \mathrm{~m} 10 & \mathrm{~m} 11 & \mathrm{~m} 12 \\ \mathrm{~m} 1 & 0 & 1 & 0 & 0 & 0 & 0 & 0 & 0 & 0 & 0 & 0 & 0 \\ \mathrm{~m} 2 & 0 & 0 & 0 & 1 & 0 & 0 & 0 & 0 & 0 & 0 & 0 & 0 \\ \mathrm{~m} 3 & 0 & 0 & 0 & 1 & 0 & 0 & 0 & 0 & 0 & 0 & 0 & 0 \\ \mathrm{~m} 4 & 0 & 0 & 0 & 0 & 1 & 0 & 0 & 0 & 0 & 0 & 0 & 0 \\ \mathrm{~m} 5 & 0 & 0 & 0 & 0 & 0 & 0 & 0 & 1 & 0 & 0 & 0 & 0 \\ \mathrm{~m} 6 & 0 & 0 & 0 & 0 & 0 & 0 & 1 & 0 & 0 & 0 & 0 & 0 \\ \mathrm{~m} 7 & 0 & 0 & 0 & 0 & 0 & 0 & 0 & 1 & 0 & 0 & 0 & 0 \\ \mathrm{~m} 8 & 0 & 0 & 0 & 0 & 0 & 0 & 0 & 0 & 1 & 0 & 0 & 0 \\ \mathrm{~m} 9 & 0 & 0 & 0 & 0 & 0 & 0 & 0 & 0 & 0 & 1 & 0 & 0 \\ \mathrm{~m} 10 & 0 & 0 & 0 & 0 & 0 & 0 & 0 & 0 & 0 & 0 & 0 & 1 \\ \mathrm{~m} 11 & 0 & 0 & 0 & 0 & 0 & 0 & 0 & 0 & 0 & 0 & 0 & 1 \\ \mathrm{~m} 12 & 0 & 0 & 0 & 0 & 0 & 0 & 0 & 0 & 0 & 0 & 0 & 0\end{array}$

Figure 4. Conjunction matrix of the original manufacturing system

\begin{tabular}{|c|c|c|c|c|c|c|c|}
\hline $\begin{array}{c}\text { Process set } \\
\text { Ma }\end{array}$ & $\mathrm{m} 1$ & $\mathrm{~m} 2$ & $\mathrm{~m} 3$ & $\mathrm{~m} 4$ & $\mathrm{~m} 5$ & $\mathrm{~m} 6$ & $\mathrm{~m} 7$ \\
\hline $\mathrm{T}=\mathrm{f}(\mathrm{Ma})$ & $\mathrm{t} 1$ & $\mathrm{t} 2$ & $\mathrm{t} 3$ & $\mathrm{t} 4$ & $\mathrm{t} 5$ & $\mathrm{t} 6$ & $\mathrm{t} 7$ \\
\hline $\mathrm{O}(\mathrm{Ta})$ & $\mathrm{p} 1$ & $\mathrm{p} 2$ & $\mathrm{p} 3$ & $\mathrm{p} 4$ & $\mathrm{p} 5$ & $\mathrm{p} 6$ & $\mathrm{p} 7$ \\
\hline $\mathrm{I}(\mathrm{Ta})$ & $\{\mathrm{p} 1\}$ & $\{\mathrm{p} 1\}$ & $\{\mathrm{p} 12\}$ & $\{\mathrm{p} 2, \mathrm{p} 3\}$ & $\{\mathrm{p} 4\}$ & $\{\mathrm{p} 13\}$ & $\{\mathrm{p} 6\}$ \\
\hline \multicolumn{7}{|l|}{} \\
\hline $\begin{array}{c}\text { Process set } \\
\text { Ma }\end{array}$ & $\mathrm{m} 8$ & $\mathrm{~m} 9$ & $\mathrm{~m} 10$ & $\mathrm{~m} 11$ & $\mathrm{~m} 12$ & $\mathrm{~m} 13$ & \\
\hline $\mathrm{T}=\mathrm{f}(\mathrm{Ma})$ & $\mathrm{t} 8$ & $\mathrm{t} 9$ & $\mathrm{t} 10$ & $\mathrm{t} 11$ & $\mathrm{t} 12$ & $\mathrm{t} 13$ & \\
\hline $\mathrm{O}(\mathrm{Ta})$ & $\mathrm{p} 8$ & $\mathrm{p} 9$ & $\mathrm{p} 10$ & $\mathrm{p} 11$ & $\mathrm{p} 12$ & $\mathrm{p} 13$ & \\
\hline $\mathrm{I}(\mathrm{Ta})$ & $\{\mathrm{p} 5, \mathrm{p} 7\}$ & $\{\mathrm{p} 8\}$ & $\{\mathrm{p} 9\}$ & $\{\mathrm{pi} 4\}$ & $\{\mathrm{p} 10, \mathrm{p} 11\}$ & $\{\mathrm{p} 10\}$ & \\
\hline
\end{tabular}

Figure 5. Conjunction matrix of the solution 1

What solution 2 adds to the original process is just the same as solution 1. Processes like scalper machine, cold mill 1 and high-gauge slitter are removed in the solution
2. There is some adjustment to the position of the polish machine as well. We can see the work flow chart in Figure 3.

We can model the reconfiguration process from the original manufacturing system to the solution 1 using the method introduced in Section 2. Assumed that the original manufacturing system is $a$, and solution 1 is $b$. The codes of each process are summarized in Table 1.

1) From the work flow chart, we get the conjunction matrix $G_{a}$ and $G_{b}$, Where $G_{a}$ is that of the original manufacturing system (See Figure 4), and $G_{b}$ is the conjunction matrix of the reconfigured manufacturing system according the solution 1 (See Figure 5).

2) The Petri Net model data of the manufacturing system before reconfiguration can be seen in Table 2 .

Table 2. Data of the Petri Net before reconfiguration

\begin{tabular}{|c|c|c|c|c|c|c|c|}
\hline $\begin{array}{l}\text { Process set } \\
\qquad M a\end{array}$ & $m_{1}$ & $m_{2}$ & $m_{3}$ & $m_{4}$ & $m_{5}$ & $m_{6}$ & $m_{7}$ \\
\hline$T=f(M a)$ & $t_{1}$ & $t_{2}$ & $t_{3}$ & $t_{4}$ & $t_{5}$ & $t_{6}$ & $t_{7}$ \\
\hline$O(T a)$ & $p_{1}$ & $p_{2}$ & $p_{3}$ & $p_{4}$ & $p_{5}$ & $p_{6}$ & $p_{7}$ \\
\hline$I(T a)$ & $\left\{p_{i 1}\right\}$ & $\left\{p_{1}\right\}$ & $\left\{p_{i 2}\right\}$ & $\left\{p_{2}, p_{3}\right\}$ & $\left\{p_{4}\right\}$ & $\left\{p_{i 3}\right\}$ & $\left\{p_{6}\right\}$ \\
\hline $\begin{array}{c}\text { Process set } \\
\qquad M a\end{array}$ & $m_{8}$ & $m_{9}$ & $m_{10}$ & $m_{11}$ & $m_{12}$ & $m_{13}$ & \\
\hline$T=f(M a)$ & $t_{8}$ & $t_{9}$ & $t_{10}$ & $t_{11}$ & $t_{12}$ & $t_{13}$ & \\
\hline$O(T a)$ & $p_{8}$ & $p_{9}$ & $p_{10}$ & $p_{11}$ & $p_{12}$ & $p_{13}$ & \\
\hline$I(T a)$ & $\left\{p_{5}, p_{7}\right\}$ & $\left\{p_{8}\right\}$ & $\left\{p_{9}\right\}$ & $\left\{p_{i 4}\right\}$ & $\left\{p_{10}, p_{11}\right\}$ & $\left\{p_{10}\right\}$ & \\
\hline
\end{tabular}




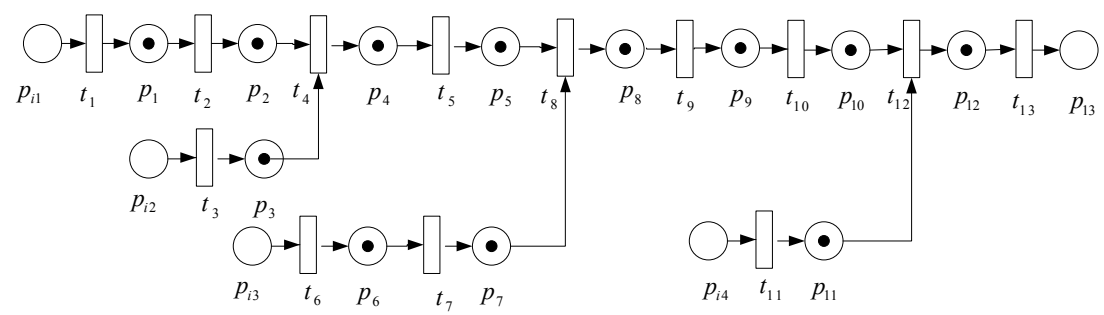

Figure 6. The Petri Net model before reconfiguration

Table 3. Data of the Petri Net after reconfiguration as per solution 1

\begin{tabular}{|c|c|c|c|c|c|c|c|}
\hline $\begin{array}{c}\text { Process set } \\
\mathrm{Ma}\end{array}$ & $\mathrm{m} 1$ & $\mathrm{~m} 2$ & $\mathrm{~m} 3$ & $\mathrm{~m} 4$ & $\mathrm{~m} 5$ & $\mathrm{~m} 8$ & $\mathrm{~m} 9$ \\
\hline $\mathrm{T}=\mathrm{f}(\mathrm{Ma})$ & $\mathrm{t} 1$ & $\mathrm{t} 2$ & $\mathrm{t} 3$ & $\mathrm{t} 4$ & t5 & t8 & t9 \\
\hline $\mathrm{O}(\mathrm{Ta})$ & $\mathrm{p} 1$ & $\mathrm{p} 2$ & $\mathrm{p} 3$ & $\mathrm{p} 4$ & p5 & $\mathrm{p} 8$ & p9 \\
\hline $\mathrm{I}(\mathrm{Ta})$ & $\{$ pi1\} & $\{\mathrm{p} 1\}$ & $\{$ pi 2$\}$ & $\{\mathrm{p} 2\}$ & $\{\mathrm{p} 3, \mathrm{p} 4\}$ & $\{\mathrm{p} 5\}$ & $\{\mathrm{p} 8\}$ \\
\hline $\begin{array}{c}\text { Process set } \\
\text { Ma }\end{array}$ & $\mathrm{m} 10$ & $\mathrm{~m} 11$ & $\mathrm{~m} 13$ & $\mathrm{~m} 14$ & $\mathrm{~m} 15$ & $\mathrm{~m} 16$ & \\
\hline $\mathrm{T}=\mathrm{f}(\mathrm{Ma})$ & $\mathrm{t} 10$ & $\mathrm{t} 11$ & $\mathrm{t} 13$ & $\mathrm{t} 14$ & $\mathrm{t} 15$ & $\mathrm{t} 16$ & \\
\hline $\mathrm{O}(\mathrm{Ta})$ & $\mathrm{p} 10$ & p11 & p13 & $\mathrm{p} 14$ & p15 & p16 & \\
\hline $\mathrm{I}(\mathrm{Ta})$ & $\{\mathrm{p} 9\}$ & $\{$ pi3 $\}$ & $\{\mathrm{p} 16\}$ & $\{$ pi4 $\}$ & $\{\mathrm{p} 10, \mathrm{p} 14\}$ & $\{\mathrm{p} 11, \mathrm{p} 15\}$ & \\
\hline
\end{tabular}

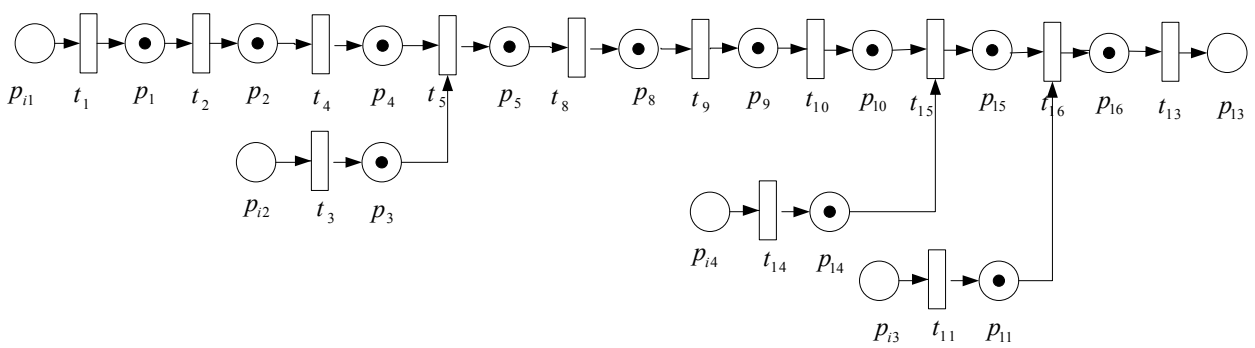

Figure 7. The Petri Net model after reconfiguration as per solution 1

\begin{tabular}{|c|c|c|c|c|c|c|c|c|c|c|c|c|}
\hline m1 & 0 & 0 & 0 & 0 & 0 & 0 & 0 & 0 & 0 & 0 & 0 & 0 \\
\hline $\mathrm{m} 2$ & 0 & 0 & 0 & 0 & 0 & 0 & 0 & 0 & 0 & 0 & 0 & 0 \\
\hline $\mathrm{m} 3$ & 0 & 0 & 0 & -1 & 1 & 0 & 0 & 0 & 0 & 0 & 0 & 0 \\
\hline $\mathrm{m} 4$ & 0 & 0 & 0 & 0 & 0 & 0 & 0 & 0 & 0 & 0 & 0 & 0 \\
\hline $\mathrm{m} 5$ & 0 & 0 & 0 & 0 & 0 & 0 & 0 & 0 & 0 & 0 & 0 & 0 \\
\hline $\mathrm{m} 8$ & 0 & 0 & 0 & 0 & 0 & 0 & 0 & 0 & 0 & 0 & 0 & 0 \\
\hline m9 & 0 & 0 & 0 & 0 & 0 & 0 & 0 & 0 & 0 & 0 & 0 & 0 \\
\hline $\mathrm{m} 10$ & 0 & 0 & 0 & 0 & 0 & 0 & 0 & 0 & 0 & 0 & 0 & 1 \\
\hline m11 & 0 & 0 & 0 & 0 & 0 & 0 & 0 & 0 & 0 & 0 & 0 & 0 \\
\hline $\mathrm{m} 13$ & 0 & 0 & 0 & 0 & 0 & 0 & 0 & 0 & 0 & 0 & 0 & 0 \\
\hline m14 & 0 & 0 & 0 & 0 & 0 & 0 & 0 & 0 & 0 & 0 & 0 & 1 \\
\hline m15 & 0 & 0 & 0 & 0 & 0 & 0 & 0 & 0 & 0 & 0 & 0 & 0 \\
\hline $\mathrm{m} 16$ & 0 & 0 & 0 & 0 & 0 & 0 & 0 & 0 & 0 & 1 & 0 & 0 \\
\hline $\mathrm{m} 6$ & 0 & 0 & 0 & 0 & 0 & 0 & 0 & 0 & 0 & 0 & 0 & 0 \\
\hline $\mathrm{m} 7$ & 0 & 0 & 0 & 0 & 0 & -1 & 0 & 0 & 0 & 0 & 0 & 0 \\
\hline $\mathrm{m} 12$ & 0 & 0 & 0 & 0 & 0 & 0 & 0 & 0 & 0 & - & 0 & 0 \\
\hline
\end{tabular}

Figure 8. Matrix $\left(A_{b}^{\prime}-A_{a}^{\prime}\right)$ obtained by simulation

The basic Petri Net graph is shown as Figure 6 (See Figure 6).

In the Figure $6, p_{i l}, p_{i 2}, p_{i 3}, p_{i 4}$ are the input places of the system, there are no limit to the capacity of them.
That indicates there could not be any downtime to the production line caused by insufficient raw materials supplement. $\mathrm{P}_{13}$ is the output place of the system. Under some specific rules the transitions in the figure above can be broken down into several sub-Petri-Nets, which can be integrated to other Petri Net model of manufacturing system.

3) Compare the two process set before and after reconfiguration, we may know that

$$
\begin{aligned}
& M^{0}=\left\{m_{1}, m_{2}, m_{3}, m_{4}, m_{5}, m_{8}, m_{9}, m_{10}, m_{11}, m_{13}\right\}, \\
& M^{+}=\left\{m_{14}, m_{15}, m_{16}\right\}, M^{-}=\left\{m_{6}, m_{7}, m_{13}\right\} .
\end{aligned}
$$

According to the reconfiguration rules, the Petri Net model data of the manufacturing system after reconfiguration as per solution 1 can be seen in Table 3 as follows:

The basic Petri Net graph is shown as Figure 7 (See Figure 7).

4) The matrix $\left(A_{b}^{\prime}-A_{a}^{\prime}\right)$ is available from Matlab simulation (See Figure 8). 
Table 4. Installation and disassemble cost in accordance with production process

\begin{tabular}{cccc}
\hline & Process set $M$ & Installation cost & Disassemble cost \\
\hline$m_{1}$ & 61.0944 & 28.5939 \\
$m_{2}$ & 7.1168 & 39.4128 \\
& $m_{3}$ & 31.428 & 50.3014 \\
& $m_{4}$ & 60.8384 & 72.198 \\
$M^{0}$ & $m_{5}$ & 17.502 & 30.6209 \\
& $m_{8}$ & 62.1027 & 11.2164 \\
& $m_{9}$ & 24.596 & 44.329 \\
& $m_{10}$ & 58.7358 & 46.6763 \\
& $m_{11}$ & 50.6053 & 1.4669 \\
\hline$M^{+}$ & $m_{13}$ & 0 & 0 \\
\hline$M^{-}$ & $m_{14}$ & 54.1419 & 72.4062 \\
& $m_{15}$ & 94.2327 & 28.1634 \\
& $m_{16}$ & 34.1759 & 26.1819 \\
\hline & $m_{6}$ & 40.1804 & 70.8471 \\
& $m_{7}$ & 30.7688 & 78.3859 \\
\hline
\end{tabular}

5) By generating random numbers for simulation, we can get equipment installation and disassemble cost in above case which is shown in Table 4 (Equipment codes are represented by process codes).

Matrix $\mathrm{J}$ defined in Section 2.5 was calculated in the simulation procedure as shown in Figure 9.

In the end, by Equation (5), we may know that the reconfiguration cost in the reconfiguration process from the original manufacturing system to solution 1 is 550.6627 ; and in the same way, we can get the reconfiguration cost of solution 2 is 558.8544. Comparing the two results, we know that solution 1 is better.

\section{Conclusions}

Cost-effective is one of the most important characters of RMS. In this paper, a model included with reconfiguration cost is constructed to RMS by utilizing DEDS modelling method Petri Net in this paper. By emphasizing differences in the process set before and after reconfiguration, a desirable reconfiguration rule has been proposed to describe the process of the manufacturing system reconfiguration. According to the method proposed in our study, we take use of Petri Net to simulate and calculate the physical reconfiguration cost more detail and exactly according to concrete reconfiguration solution, rather than just giving the estimated value or qualitative value. And this point is one of the most important differences from the other researches.

In our current study, we omit an important factor i.e. the reconfiguration time. As we know, the reconfiguration time should not be calculated simply by summing the cost of install and disassemble equipment in the reconfiguration process like reconfiguration cost. And in some cases, synchronized structure in the reconfiguration process must be taken into account.

For the future research, it is suggested that the advanced Petri Net should be taken into account to coloured tokens in the model. Then probability value is needed to be the standard for a work procedure to choose the next procedure in accordance with the production process. As for reconfiguration time of the consecutive structure, we may compute it just like the reconfiguration cost, nevertheless, the total time delay as a result of choices and synchronization structure in the reconfiguration

$\begin{array}{rrrrrrrrrrrrr}0 & 0 & 0 & 0 & 0 & 0 & 0 & 0 & 0 & 0 & 0 & 0 & 0 \\ 0 & 0 & 0 & 0 & 0 & 0 & 0 & 0 & 0 & 0 & 0 & 0 & 0 \\ 0 & 0 & 0 & 50.3014 & 31.4280 & 0 & 0 & 0 & 0 & 0 & 0 & 0 & 0 \\ 0 & 0 & 0 & 0 & 0 & 0 & 0 & 0 & 0 & 0 & 0 & 0 & 0 \\ 0 & 0 & 0 & 0 & 0 & 0 & 0 & 0 & 0 & 0 & 0 & 0 & 0 \\ 0 & 0 & 0 & 0 & 0 & 0 & 0 & 0 & 0 & 0 & 0 & 0 & 0 \\ 0 & 0 & 0 & 0 & 0 & 0 & 0 & 0 & 0 & 0 & 0 & 0 & 0 \\ 0 & 0 & 0 & 0 & 0 & 0 & 0 & 0 & 0 & 0 & 0 & 58.7358 & 0 \\ 0 & 0 & 0 & 0 & 0 & 0 & 0 & 0 & 0 & 0 & 0 & 0 & 50.6053 \\ 0 & 0 & 0 & 0 & 0 & 0 & 0 & 0 & 0 & 0 & 0 & 0 & 0 \\ 0 & 0 & 0 & 0 & 0 & 0 & 0 & 0 & 0 & 0 & 0 & 54.1419 & 0 \\ 0 & 0 & 0 & 0 & 0 & 0 & 0 & 0 & 0 & 0 & 0 & 0 & 94.2327 \\ 0 & 0 & 0 & 0 & 0 & 0 & 0 & 0 & 0 & 34.1759 & 0 & 0 & 0 \\ 0 & 0 & 0 & 0 & 0 & 0 & 0 & 0 & 0 & 0 & 0 & 0 & 0 \\ 0 & 0 & 0 & 0 & 0 & 78.3859 & 0 & 0 & 0 & 0 & 0 & 0 & 0 \\ 0 & 0 & 0 & 0 & 0 & 0 & 0 & 0 & 0 & 98.6158 & 0 & 0 & 0\end{array}$

Figure 9. Matrix J obtained by Matlab simulation 
process need further study to elaborate how to involve reconfiguration time into the model and calculate it.

\section{Acknowledgments}

This work was supported by Natural Science Foundation of China under Grant No. 70672088 and No.70931002.

\section{REFERENCES}

[1] Y. koren, U. Heisel, T. Moriwaki, G. Pritchow, H. VanBrussel, and G. Ulsoy, "A Reconfigurable Manufacturing Systems [C]," Annals of the CIRP, Vol. 48, No. 2, 1999.

[2] M. G. Mehrabi, A. G. Ulsoy, and Y. Korren, "Reconfigurable manufacturing systems: Key to future manufacturing [J]," Journal of Intelligent Manufacturing, Vol. 11, pp. 403-419, 2000.

[3] C. E. Wang, "On the possibility of manufacturing system reconfiguration $[\mathrm{J}]$," Computer Integrated Manufacturing System, Vol. 6, No. 4, pp. 1-5, 2000.

[4] F. J. Liang and R. X. Nin, "Reconfigurable Manufacturing System Theory [J]," Chinese Journal of Mechanical Engineering, Vol. 39, No. 6, pp. 36-43, 2003.

[5] H. M. Yuan, D. B. Li, M. J. Yu, and K. J. Zhou, "Research on evaluation system for reconfigurable manufacturing systems [J]," Chinese Mechanical Engineering, Vol. 18, No. 7, pp. 2050-2055, 2007.

[6] J. P. Dou, X. Z. Dai, and Z. D. MENG, "Configuration selection of reconfigurable manufacturing system based on hybrid analytical hierarchy process [J]," Computer Integrated Manufacturing System, Vol. 13, No. 7, pp. 1360-1366, 2007.

[7] Z. J. Wu, R. X. Nin, and A. M. Wang, "Grey Fuzzy Synthetically Evaluation Method for RMS Layout Planning [J]," Chinese Mechanical Engineering, Vol. 18, No. 19, pp. 2313-2317, 2007.

[8] F. F. de Lamotte, "Evaluation of reconfigurable manufacturing systems configurations using tolerance criteria $[\mathrm{J}]$," IEEE, pp. 3715-3720, 2006.

[9] R. Galan, J. Racero, I. Eguia, and D. Canca, "A methodology for facilitating reconfiguration in manufacturing: the move towards reconfigurable manufacturing systems [J]," International Journal of Advanced Manufacturing Technology, Vol. 33, pp. 345-353, 2007.

[10] C. H. Kuo, "Resource allocation and performance evaluation of the reconfigurable manufacturing systems [C]." Proceedings of the IEEE International Conference on Systems, Man and Cybernetics, pp. 2452-2456, 2001.

[11] Y. T. Cai, X. D. Yang, and X. M. Yan, "Reconfiguration Algorithm for Reconfigurable Manufacturing System [J]," Journal of Computer Aided Design and Graphics, Vol. 15, No. 2, pp. 162-173, 2003.

[12] F. Wang and D. Xu, et al., "Petri NET modeling and Analyzing for RMS [J]," Controlling and Decision Making, Vol. 20, No. 6, 2005.

[13] R. Kumar, S. Kumar, and M. K. Tiwari, "An expert enhanced colored fuzzy Petri net approach to reconfigurable manufacturing systems involving information delays [J]," International Journal of Advanced Manufacturing Technology, Vol. 26, pp. 922-933, 2005.

[14] A. M. Deif and W. ElMaraghy, "Effect of reconfiguration costs on planning for capacity scalability in reconfigurable manufacturing systems [J]," International Journal of Flexible Manufacturing System, Vol. 18, pp. 225-238, 2006.

[15] F. J. Liang and R. X. Nin, "Cost model for reconfigurable manufacturing system [J]," Chinese Mechanical Engineering, Vol. 14, No. 23, pp. 2023-2028, 2003. 